\title{
¿UN DERECHO INTERNACIONAL DEL DEPORTE? REFLEXIONES EN TORNO A UNA RAMA DEL DERECHO INTERNACIONAL PÚBLICO IN STATU NASCENDI
}

"I am always amazed when I hear people saying that sport creates goodwill between the nations, and that if only the common peoples of the world could meet one another at football or cricket, they would have no inclination to meet on the battlefield».

George ORWELL, The Sporting Spirit (1945)

Carmen PÉREz GonZÁLEZ*

SUMARIO: 1. CUESTIONES INTRODUCTORIAS.-2. LAS RELACIONES ENTRE EL DEPORTE Y EL DERECHO INTERNACIONAL: LA REGULACIÓN DEL DEPORTE INTERNACIONAL.-3. DERECHO INTERNACIONAL PÚBLICO Y DEPORTE.-3.1. Deporte, paz y cooperación al desarrollo.-3.2. El Derecho internacional público al servicio de la prevención y erradicación de determinadas conductas «antideportivas».-3.3. Deporte y Derecho Internacional de los Derechos Humanos.-3.3.1. Deporte y promoción de los derechos humanos.-3.3.2. ¿Un derecho humano al deporte?-3.3.3. La protección de los derechos humanos de los deportistas. - a) La protección de los derechos de los menores deportistas. - b) La protección en el ámbito de la lucha contra el dopaje en el deporte.-4. CONCLUSIONES.

\section{CUESTIONES INTRODUCTORIAS}

No han sido infrecuentes los análisis que se acercan a la realidad del fenómeno deportivo desde un punto de visto politológico, sociológico y/o económico. Más reciente es, sin duda, el interés académico por los problemas que suscitan las relaciones entre el Derecho y la actividad deportiva ${ }^{1}$. Esto es particularmente cierto en lo que hace al Derecho público. En 1989 alertaba François Rigaux de que la explotación económica del deporte (y del

\footnotetext{
* Profesora Titular de Derecho internacional público y Relaciones Internacionales, Universidad Carlos III de Madrid. Email: carmen.perez@uc3m.es.

1 Son pioneros en este sentido, en España, los estudios de Bermejo Vera, J., Constitución y deporte, Madrid, Tecnos, 1998, y Cazorla Prieto, L. M., Deporte y Estado, Barcelona, Labor, 1979. Desde la perspectiva del Derecho internacional debe citarse a KARAQuillo, J.-P., «Droit international du sport», RCADI, 2004, núm. 309, pp. 9-124, y NAFZIGER, J. A. R., «International Sports Law: A reply of characteristics and trends», AJIL, vol. 86, 2002, pp. 489-518.
} 
entretenimiento) había logrado sustraerse al control estatal. Se trata, afirmaba, "de una vaca sagrada que ningún gobierno osaría reducir a la condición de animal doméstico» ${ }^{2}$. Ese proceso, sin embargo, se está revirtiendo. Alimentado por el Derecho administrativo, mercantil, laboral o financiero se ha ido configurando progresivamente una nueva disciplina, el Derecho deportivo (o del deporte), que cuenta ya con una entidad propia ${ }^{3}$. Si bien el Derecho internacional público no ha permanecido al margen de ese proceso, el interés mostrado hasta ahora por la academia ha sido notoriamente escaso $^{4}$.

Y, sin embargo, se plantean en el ámbito deportivo cuestiones de enorme interés para los iusinternacionalistas ${ }^{5}$. Debe tenerse en cuenta que el Derecho internacional no ha permanecido absolutamente al margen de la regulación de cuestiones de índole deportiva. Así, la cooperación internacional ha dado hasta ahora resultados relevantes en ámbitos como la lucha contra el dopaje o el amaño de partidos. En otro orden de cosas, parece oportuno explorar si, junto a ello, la configuración en el plano internacional del derecho al deporte como un derecho fundamental ${ }^{6}$ o la promoción de la paz y el desarrollo a través del deporte auspiciada por algunas Organizaciones Internacionales, siendo pionera en este sentido Naciones Unidas (NNUU) ${ }^{7}$,

2 RigauX, F., «Les situations juridiques individuelles dans un système de relativité générale. Cours général de droit international privé», RCADI, 1989-I, núm. 213, p. 379.

3 No es esta una opinión unánimemente compartida. Tal y como nos recuerda Franck Latty, algunos autores han negado su existencia como un área jurídica autónoma. Grayson, por ejemplo, ha afirmado lo siguiente: "No subject exists which jurisprudentially can be called sports law. As a soundbite headline, shorthand description, it has no juridical foundation; for common law and equity create no concept of law exclusively relating to sport. Each area of law applicable to sport does not differ from how it is found in any social or jurisprudential category» (citado por LATTY, F., "Transnational Sports Law», en VIEweg, K. (ed.), Lex Sportiva, Berlín, Duncker \& Humblot, 2015, p. 108).

${ }^{4}$ Constituye sin duda una excepción, tal y como se irá mostrando a lo largo de este trabajo, el Derecho de la Unión Europea (UE). Las diferentes cuestiones que se plantean en torno a la relación entre la actividad deportiva y el Derecho de la UE vienen siendo, desde hace décadas, objeto de análisis por parte de la doctrina. A ese interés ha contribuido sin duda el hecho de que el Tribunal de Justicia haya dictado un nutrido grupo de sentencias que han impactado de modo relevante en los esquemas propios de la organización de la actividad deportiva. La aplicación de las denominadas libertades comunitarias y de las reglas del Derecho de la competencia a dicha actividad, en cuanto constituyese actividad económica, ha traído como consecuencia, no sin tensiones, la derogación de algunas reglas deportivas y la adaptación de otras. Sobre estas cuestiones, véase PARRISH, R., "Lex sportiva and EU Sports Law», European Law Review, vol. 37, 2012, núm. 6, pp. 716-733; MıÈGE, C., «Existe-il (encore) une spécificité du sport au regard du Droit de l'Union européene?», Cahiers du Droit du Sport, 2016, núm. 44, pp. 38-42; y WeATHERILl, S., European Sports Law. Collected Papers, La Haya, Asser Press, 2014.

5 De acuerdo con Jean-Pierre Karaquillo, la reflexión sobre un «Derecho internacional del deporte» es al tiempo «embriagadora y audaz»: KARAQUILLO. J.-P., op. cit., nota 1, p. 22.

6 En 1978, la 20. ${ }^{\text {a }}$ Conferencia General de la UNESCO aprobó la Carta Internacional de la Educación Física y el Deporte, que ha sido revisada en noviembre de 2015. Su artículo primero establece que «(l)a práctica de la educación física, la actividad física y el deporte es un derecho fundamental para todos». El texto de la Carta está disponible en http://www.unesco.org/new/es/social-and-human-sciences/ themes/physical-education-and-sport/sport-charter/what-is-the-charter/ (todos los documentos electrónicos citados a lo largo del trabajo han sido consultados por última vez el 31 de octubre de 2016).

7 En 2011, la Asamblea General de Naciones Unidas (AGNU) decidió incluir en su agenda el subtema «El deporte para la paz y el desarrollo: construcción de un mundo pacífico y mejor mediante el 
permitirían hablar de la existencia de un sector propio del Derecho internacional: el Derecho internacional del deporte. Ese es el propósito último de esta reflexión. En cualquier caso, el análisis debe partir del examen de la regulación del deporte internacional y, en particular, del papel que en dicha regulación juegan las organizaciones deportivas internacionales. Me refiero, en particular, al Comité Olímpico Internacional (COI) y a las federaciones deportivas internacionales.

Debe advertirse, por último, que quedará al margen del trabajo el papel que el deporte juega en el ámbito de las relaciones internacionales ${ }^{8}$. La poderosa relación entre deporte y política impulsa a los Estados y otros sujetos y actores internacionales no solo a servirse de su potencial para mejorar su imagen ${ }^{9}$ e influencia en el plano internacional ${ }^{10}$, sino incluso a aprovechar la capacidad de los grandes eventos deportivos para visibilizar ciertas causas ${ }^{11}$.

\section{LAS RELACIONES ENTRE EL DEPORTE Y EL DERECHO INTERNACIONAL: LA REGULACIÓN DEL DEPORTE INTERNACIONAL}

Este estudio parte de la premisa de que los avances mencionados, que serán objeto de un análisis detallado a continuación, permitirían en efecto hablar de la configuración de un nuevo sector del Derecho internacional público, al que denominamos Derecho internacional del deporte. Algunos autores ya han teorizado sobre su existencia, definiéndolo, por ejemplo, como el

deporte y el ideal olímpico" y examinarlo cada dos años: véase la Resolución 66/5, de 8 de diciembre (A/RES/66/5), disponible en $h t t p: / / w w w . u n . o r g / e s / c o m u n / d o c s / ? s y m b o l=A / R E S / 66 / 5$. Todas las iniciativas adoptadas por la Organización en este ámbito pueden consultarse en la siguiente dirección electrónica: http://www.un.org/sport/.

${ }^{8}$ Sobre esta cuestión, véase LEVERMORE, R. y Budd, A. (eds.), Sport and International Relations. An Emerging Relationship, Londres, Routledge, 2004.

9 «Sport, like any artistic or scientific achievement, is a legitimate means of national representation»: Vedder, CH., «The International Olympic Committee: An Advanced Non-Governmental Organization and the International Law», German Yearbook of International Law, vol. 27, 1984, p. 233.

10 Un buen número de Estados han recurrido al deporte como herramienta diplomática, como una suerte de «poder suave» (soft power) con ese propósito. Pueden citarse, a título de ejemplo, la reciente adopción en Australia de una "Estrategia en materia de diplomacia deportiva 2015-2018» (http://dfat. gov.au/about-us/publications/Pages/australian-sports-diplomacy-strategy-2015-18.aspx) o el también reciente nombramiento en Francia de un «Embajador del deporte». Y, de nuevo, la UE ofrece ejemplos interesantes. La Comisión Europea ha adoptado en 2016 un Informe sobre «Diplomacia deportiva» en un intento de configurar el deporte como una herramienta que sirva para potenciar los valores europeos en el exterior y ayudar a la consecución de los objetivos de la Organización en el ámbito de las relaciones exteriores. El Informe está disponible en http://ec.europa.eu/sport/library/policy_documents/ hlg-sport-diplomacy-final_en.pdf.

${ }_{11}$ "A bomb in the White House, a mine in the Vatican, the death of Mao-Tse-tung, an earthquake in Paris could not have echoed through the consciousness of every man in the world like the operation at Munich [...] the choice of the Olympics, from a purely propagandistic viewpoint was 100 percent successful. It was like painting the name of Palestine on a mountain that can be seen from the four corners of the earth»: las palabras son de un portavoz del Grupo Septiembre Negro, citado por ToOHEY, K., «Terrorism, sport and public policy in the risk society», Sport in Society, vol. 11, 2008, núm. 4, p. 434. 
conjunto de reglas, principios, procedimientos y prácticas que se aplican a la organización y regulación de la actividad deportiva transnacional ${ }^{12}$ o como el conjunto de normas de Derecho público que se aplican a cuestiones jurídicas relativas al deporte y que directa o indirectamente conciernen a los sujetos de Derecho internacional ${ }^{13}$.

Conviene señalar que cualquier aproximación a esta cuestión debe partir de la existencia de un sistema deportivo internacional que opera como un sistema privado, autocontenido, y que pivota, como se ha señalado, sobre la acción del COI y las federaciones deportivas internacionales. Estas últimas son las responsables de la organización de la actividad deportiva de cada disciplina en el plano internacional. Desde un punto de vista jurídico, son asociaciones de Derecho privado en las que se integran las asociaciones deportivas nacionales (o federaciones) de la disciplina correspondiente ${ }^{14}$. Organizan y coordinan sus propias competiciones de modo autónomo y defienden la existencia de una supuesta "especificidad» de la actividad deportiva como un modo de preservar su autonomía regulatoria y aplicar sus propias reglas ${ }^{15}$, que conforman una suerte de Lex Sportiva ${ }^{16}$. Los problemas surgen cuando aquellas reglas o procedimientos contravienen principios esenciales del Derecho asumidos por el Derecho internacional ${ }^{17}$. La emergencia de mecanismos privados de solución de controversias en el ámbito deportivo a través de un sistema de tribunales u órganos arbitrales nacionales e internacionales - del que el Tribunal Arbitral del Deporte (CAS, en sus siglas en inglés) ${ }^{18}$ es el último escalón- busca precisamente evitar la intervención de los tribunales or-

12 He tomado esta definición de NAFzIgER, J. A. R., «Defining the Scope and Structure of International Sports Law: Four Conceptual Issues», International Sports Law Journal, 2011, núms. 3-4, p. 14.

13 WAX, A., "Public International Sports Law-A “Forgotten” Discipline?», International Sports Law Journal, 2010, núms. 3-4, p. 25.

14 "Cette unification des règles de chacun des sports est devenue le rôle essential des federations internationales sportives»: SILANCE, L., "La logique, le sport et les ordres juridiques», en INGBER, L. y HaArscher, G. (eds.), Justice et argumentation. Essais à la mémoire de Chaïm Perelman, Bruselas, Ed. de l'Université Libre de Bruxelles, 1986, p. 40.

15 "International and national sports federations create, apply and enforce rules in order to regulate their sport. Associated athletes and clubs are required to comply with these rules, which are laid down in the federations' regulations. If they do not abide by the rules, a disciplinary sanction can be imposed. These sanctions can range from a fine, to the exclusion of participation in certain matches, and in extreme cases even to exclusion from the federation»: VAN KLEEF, R., "Reviewing Disciplinary Sanctions in Sports», Cambridge Journal of International and Comparative Law, vol. 4, 2015, núm. 1, pp. 3-4.

16 Definida como "the body of sports law generated by the sports movement and applied globally by the Court of Arbitration for Sport»: PARRISH, R., op. cit., nota 4, p. 733.

17 "The literature is replete with examples of rulings by national and international sports associations and of the Court of Arbitration for Sport (CAS) which appear to be harsh and to involve the application of stringent standards in an inflexible way»: BYRnES, A., "Human Rights and the Anti-Doping Lex Sportiva. The Relationship of Public and Private International Law, "Law Beyond the State" and the Laws of Nation States», en HaAs, U. y Healey, D. (eds.), Doping in Sport and the Law, Oxford y Portland, Hart Publishing, 2016, p. 82.

18 Sobre esta institución puede verse: Simma, B., "The Court of Arbitration for Sport», en BöcKSTIEgel, K.-H., Folz, H.-E., Mössner, J. M. y ZemaneK, K. (eds.), Völkerrecht. Recht der Internationalen Organisationen. Weltwirtschaftsrecht. Festschrift für Ignaz Seidl-Hohenveldern, Colonia, Heymann, 1988, pp. 573-585, y VaITIEKunAS, A., The Court of Arbitration for Sport: Law-Making and the Question of Independence, Berna, Stämpfli Verlag, 2014. 
dinarios ${ }^{19}$. Sin embargo, en los últimos años, las autoridades deportivas han visto cómo autoridades públicas internas y Organizaciones Internaciones les reclamaban un mayor respeto de los principios democráticos, una mayor transparencia y una adecuada protección de los derechos fundamentales de los deportistas.

Tal y como se ha señalado repetidamente, en la ordenación de «lo deportivo» intervienen normas de Derecho público y privado y normas emanadas de las organizaciones deportivas. Esas normas son, en todos los casos, tanto internas como internacionales ${ }^{20}$. En este último plano, aquellas organizaciones han creado, sobre la base de su facultad de autorregulación ${ }^{21}$, un conjunto de reglas y principios que ha sido denominado «Derecho transnacional del deporte» ${ }^{22}$, «Derecho global del deporte» ${ }^{23}$ y, más recientemente, «Lex

19 Es posible, sin embargo, al menos en los países de nuestro entorno, que las decisiones que se toman en sede federativa en materia disciplinaria sean revisadas por los tribunales ordinarios, aunque esa revisión se limite, en general, a verificar que los órganos disciplinarios federativos han respetado principios generales como el de legalidad o proporcionalidad: VAN KLEEF, R., op. cit., nota 15, pp. 11-12. En España, el Tribunal Administrativo del Deporte, un órgano colegiado adscrito al Consejo Superior de Deportes, conoce de los recursos contra las decisiones federativas. Sus resoluciones agotan la vía administrativa y son recurribles en vía contenciosa: cfr. los arts. 1 y 10 del Real Decreto 53/2014, de 31 de enero, por el que se desarrolla la composición, organización y funciones del Tribunal Administrativo del Deporte, BOE núm. 28, de 1 de febrero de 2014.

20 "The governance of global sport, including the Olympics, involves considerable administration by private bodies and by hybrid public-private bodies»: VAN VAERENBERGH, A., "Regulatory Features and Administrative Law Dimensions of the Olympic Movement's Anti-Doping Regime», IILJ Working Paper 2005/11 (Global Administrative Law Series), p. 1, disponible en http://www.iilj.org/oldbak/papers/ IILJ2005.11Vaerenbergh.html.

21 En el seno de la UE, este poder de autorregulación fue expresamente reconocido en la Declaración de Niza de diciembre de 2000 sobre las características del deporte y su función social en Europa. En la misma, el Consejo Europeo apoya la independencia de las organizaciones deportivas y su derecho a organizarse a través de las estructuras asociativas que resulten apropiadas. Esa independencia, sin embargo, se condiciona en la Declaración al respeto por parte de estas organizaciones a la normativa interna y comunitaria y a que su actuación responda a principios democráticos y sea transparente. La Declaración de Niza está disponible en https://www.consilium.europa.eu/uedocs/cms_data/docs/pressdata/en/ec/00400-r1.\%20ann.en0.htm. Sobre la especificidad del deporte y el Derecho de la UE, véase Parrish, R. y Miettinen, S., The Sporting Exception in European Union Law, La Haya, T. M. C. Asser Press, 2008. Hasta el Tratado de Lisboa, los Estados miembros de la UE no atribuyeron expresamente a la Organización una competencia en materia de deporte. Desde entonces, el art. 165.1 del Tratado de Funcionamiento de la UE (TFUE) establece que «la Unión contribuirá a fomentar los aspectos europeos del deporte, teniendo en cuenta sus características específicas, sus estructuras basadas en el voluntariado y su función social y educativa». Sobre la incorporación de una competencia específica en materia de deporte en el Derecho originario es interesante el trabajo de GARcía, B. y WEATHERILL, S., «Engaging with the EU in order to Minimize its Impact: Sports and the Negotiations of the Treaty of Lisbon», Journal of European Public Policy, vol. 19, 2012, núm. 2, pp. 238-256.

22 François Rigaux consideró en 1989 que había múltiples sistemas transnacionales de Derecho deportivo: "(i)l n'existe pas "un" ordre juridique sportif transnational, chaque sport particulier étant régi par un système autonome, chaque relève-t-on une grande convergence entre les règles et les pratiques observés par chacun de ces systems particuliers, mails ils sont tous indépendants les uns des autres»: RIGAUX, F., op. cit., nota 2, p. 285.

${ }^{23}$ De acuerdo con Ken Foster, cabe distinguir entre Derecho del deporte «internacional» y «global». Este autor define el «Derecho internacional del deporte» como «el conjunto de principios de Derecho internacional aplicables al deporte» y el «Derecho global del deporte» como «un orden jurídico transnacional autónomo creado por instituciones deportivas globales que gobiernan el deporte internacional»: Foster, K., «Is There a Global Sports Law?», Entertainment Law, vol. 2, 2003, núm. 1, pp. 1-2. 
Sportiva» ${ }^{24}$. Lo que parece innegable es que una pluralidad de órdenes jurídicos inciden en la regulación de la actividad deportiva. Desde luego, este pluralismo jurídico no es privativo del orden deportivo ${ }^{25}$. Bien al contrario, el deporte constituiría un ejemplo del desarrollo de sistemas sociales y normativos autónomos al que conduce lo que se ha denominado la «globalización policéntrica ${ }^{26}$.

Este trabajo pretende centrarse, únicamente, en el papel que estaría llamado a jugar el Derecho internacional público en este ámbito. De un lado, como fuente propia del Derecho internacional del deporte: tal y como se verá a lo largo del mismo, diversos tratados internacionales y múltiples resoluciones de diferentes Organizaciones Internacionales se dirigen a regular la conducta de sujetos de Derecho internacional, principalmente los Estados, en relación con cuestiones deportivas de diversa índole, bien para obligarles a la proscripción de determinados fenómenos, como el dopaje o el amaño de partidos, bien para fomentar la consecución de determinados objetivos. De otro, el Derecho internacional público, en particular el Derecho Internacional de los Derechos Humanos (DIDH) podría servir de límite a la acción de las organizaciones deportivas. En este sentido, el DIDH, cuando opera en el marco deportivo, serviría de escudo frente a eventuales vulneraciones de derechos humanos de los deportistas que quedarían, de otro modo, en dicho entorno.

\section{DERECHO INTERNACIONAL PÚBLICO Y DEPORTE}

\subsection{Deporte, paz y cooperación al desarrollo}

Existe un consenso creciente en torno a la idea de que el deporte puede considerarse una herramienta útil para la consecución de objetivos propios del Derecho internacional contemporáneo, siendo la paz y el desarrollo ${ }^{27}$ dos ejemplo claros en este sentido ${ }^{28}$. Las Organizaciones Internacionales han sido conscientes de este potencial. El caso de NNUU es sin duda paradigmático ${ }^{29}$. La Organización cuenta con una «Oficina del Deporte para el desarrollo y la

\footnotetext{
24 Véase supra, nota 16.

25 Tal y como nos recuerda Emmanuelle Jouannet, «la oposición tradicional entre Derecho internacional público y Derecho internacional o transnacional privado ha entremezclado desde hace tiempo sus campos de aplicación de la misma manera en que se han densificado, en favor de esta evaluación, las interrelaciones entre actores tradicionales, públicos, y operadores privados»: JouANNET, E., «¿De qué sirve el Derecho internacional? El Derecho internacional providencia del siglo XXI», Revista de Derecho Público, 2011, núm. 27, p. 11. Este es, no cabe duda, el caso del deporte.

${ }^{26}$ Fischer-Lescano, A. y Teubner, G., «Regime-Collisions: The Vain Search for Legal Unity in the Fragmentation of Global Law», Michigan Journal of International Law, vol. 25, 2004, p. 1006.

27 Roger Levermore denunció en 2008 la ausencia de investigación académica sobre esta cuestión: Levermore, R., «Sport: a new engine for development?», Progress in Development Studies, vol. 8, 2008, núm. 2, pp. 183-184.

${ }^{28}$ Véase, al respecto, BeUtLER, I., «Sport serving development and peace: Achieving the goals of the United Nations through sport», Sport in Society, vol. 11, 2008, núm. 4, pp. 359-369.

29 Véase supra nota 7.
} 
paz» y el secretario general nombró en 2008 a un asesor especial sobre esta cuestión.

En otro orden de cosas, debe recordarse también que la denominada tre-

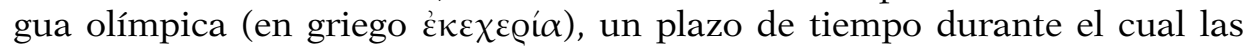
guerras se suspendían de modo temporal para facilitar que los deportistas pudieran desplazarse a Olimpia de modo seguro para participar en los Juegos y volver después a sus lugares de origen en paz, fue «resucitada» por el COI en $1992^{30}$. Y que en 1993, en su Resolución 48/11, la AGNU instó a los Estados miembros a observarla ${ }^{31}$. Este llamamiento fue reiterado en el año 2000 en la denominada Declaración del Milenio ${ }^{32}$.

\subsection{El Derecho internacional público al servicio de la prevención y erradicación de determinadas conductas "antideportivas»}

Tal y como ya se ha advertido, los Estados han recurrido, bajo los auspicios de determinadas Organizaciones Internacionales, a la adopción de tratados internacionales cuyo objetivo es la prevención y erradicación de conductas que atentarían contra los valores deportivos. Pueden mencionarse, a título de ejemplo, el dopaje y la manipulación de las competiciones deportivas.

Estados, Organizaciones Internacionales, organizaciones deportivas y atletas parecen mostrarse de acuerdo en considerar que el dopaje es perjudicial para la salud y contrario al fair play. Puede afirmarse la existencia de un consenso internacional ${ }^{33}$ en torno a la idea de que el recurso al dopaje en el deporte debe prohibirse o, al menos, limitarse ${ }^{34}$. En general, este consenso se funda en dos razones. De un lado, la prohibición se conecta con la protección de ciertos derechos fundamentales del deportista. En particular, el derecho a la salud. Por la misma razón, y en la medida en que cabría consi-

30 El llamamiento del COI fue hecho suyo por los Comités Olímpicos de 184 Estados y había sido también apoyado por la Asamblea de Jefes de Estado y de Gobierno de la, entonces, Organización para la Unidad Africana.

31 A/RES/48/11, de 2 de noviembre de 1993, disponible en http://www.un.org/es/comun/ docs/?symbol=A/RES/48/11.

$32 \mathrm{~A} / \mathrm{RES} / 55 / 2$, de 13 de septiembre de 2000, disponible en http://www.un.org/spanish/milenio/ ares552.pdf.

33 En la Resolución 58/5, relativa al deporte como medio de promover la educación, la salud, el desarrollo y la paz (A/RES/58/5, de 17 de noviembre de 2003), la AGNU invitaba a los gobiernos a acelerar la elaboración de una convención internacional contra el dopaje en todas las actividades deportivas e instaba a la UNESCO a que, en colaboración con otras Organizaciones Internacionales y regionales competentes, coordinase su elaboración. Apenas dos años después, la Convención de la UNESCO contra el dopaje en el deporte, a la que nos referiremos enseguida, era una realidad. La resolución está disponible en http://www.un.org/es/comun/docs/?symbol=A/RES/58/5.

${ }^{34}$ Hay también argumentos a favor de su uso. Uno de los defensores más reputados de su legalización es el Prof. Julian Savulesku, del Centro Uehiro de ética práctica de la Universidad de Oxford. Una lista de sus publicaciones está disponible en http://www.practicalethics.ox.ac.uk/staff/staff/director/ julian_savulescu. Véase también, Pérez Triviño, J. L., The Challenges of Modern Sport to Ethics. From Doping to Cyborgs, Maryland, Lexington Books, 2013. 
derar el dopaje en el deporte una cuestión de salud pública, su prevención y erradicación requeriría la intervención de las autoridades públicas. De otro lado, la prohibición del dopaje constituye un modo de proteger un «interés colectivo»: dado que proporciona una ventaja injusta, incluso inmoral, el dopaje rompe las reglas del juego limpio y contribuye a debilitar la confianza de los espectadores en la integridad de las competiciones ${ }^{35}$. Lo que interesa destacar aquí es que la prohibición del dopaje no se contiene únicamente en normas deportivas de naturaleza privada, sino también en instrumentos internacionales de naturaleza convencional ${ }^{36}$. Junto a estos tratados internacionales, debe mencionarse la adopción, en el ámbito europeo ${ }^{37}$, de un importante número de instrumentos de soft law, tales como recomendaciones del Consejo de Ministros del Consejo de Europa ${ }^{38}$ o comunicaciones de la Comisión Europea ${ }^{39}$.

La manipulación de las competiciones deportivas es otro de los fenómenos que, asociado a la corrupción en el deporte, ha merecido la atención de Estados y Organizaciones Internacionales. De nuevo, el Consejo de Europa ha sido pionero en el impulso de instrumentos vinculantes para afrontar este problema. Un Convenio Europeo sobre la manipulación de las competiciones deportivas, que aún no ha entrado en vigor, se adoptó el 18 de septiembre de $2014^{40}$.

35 Véase al respecto, Pérez González, C., Las obligaciones de los Estados en materia de prevención, control y sanción del dopaje en el deporte, Cizur Menor, Aranzadi, 2008, pp. 23-35.

36 El Consejo de Europa fue la primera Organización Internacional que impulsó la adopción de un tratado internacional que imponía a sus Estados parte obligaciones específicas con el objetivo de erradicar ese fenómeno. Se trata del Convenio europeo contra el dopaje en el deporte, que se adoptó el 16 de noviembre de 1989 y entró en vigor el 1 de marzo de 1990 (BOE núm. 140, de 11 de junio de 1992). Está disponible en http://www.conventions.coe.int/Treaty/Commun/QueVoulezVous.asp? $N T=135$ $\& C M=8 \& D F=02 / 12 / 2014 \& C L=E N G$. Años más tarde, se aprobó en el seno de la UNESCO la Convención internacional contra el dopaje en el deporte. La misma fue adoptada el 19 de octubre de 2005 y entró en vigor el 1 de febrero de 2007 (BOE núm. 41, de 16 de febrero de 2007). En el momento en el que se escriben estas líneas 177 Estados son parte en la misma. El texto de la Convención está disponible en http://portal.unesco.org/es/ev.php-URL_ID=31037\&URL_DO=DO_TOPIC\&URL_SECTION=201.html. Tal y como se ha señalado, se trata del primer instrumento internacional universal y vinculante adoptado para acabar con el dopaje en el deporte: NAFZIGER, J. A. R., «The Future of International Sports Law», Willamette Law Journal, vol. 42, 2006, núm. 4, p. 874. Sobre la misma, véase PaLOMAR OlmEDA, A., "La Convención internacional de la UNESCO contra el dopaje en el deporte», Revista Española de Derecho Deportivo, 2005, núm. 16, pp. 9-36.

37 Fuera del ámbito europeo debe citarse el Consejo Iberoamericano del Deporte, creado el 4 de agosto de 1994 mediante el Tratado de Montevideo. En virtud de su art. 3.g), entre los objetivos de la Organización está la promoción de la ética en el deporte y la práctica del juego limpio. El Tratado de Montevideo está disponible en http://www.coniberodeporte.org/es/.

${ }_{38}$ Véase, por ejemplo, la Recomendación R (84) 19, relativa a una «Carta Europea contra el dopaje en el deporte» disponible en http://www.coe.int/t/cm/adoptedTexts_en.asp.

39 Entre las que cabe destacar la «Comunicación de la Comisión al Consejo, al Parlamento Europeo, al Comité Económico y Social y al Comité de las Regiones: Plan de apoyo comunitario a la lucha contra el dopaje en el deporte» COM (1999) 643 final, disponible en http:/leuropa.eu/legislation_summaries/education_training_youth/sport/l35003_es.htm.

40 Está disponible en http://www.coe.int/en/web/conventions/full-list/-/conventions/treaty/215. Mediante Auto del presidente del Tribunal de Justicia de la UE de 1 de septiembre de 2015 (Dictamen 1/14, ECLI:EU:C:2015:607) se decidió el archivo de la solicitud de Dictamen de Malta sobre la compatibilidad del Convenio con algunas disposiciones del TFUE. 


\subsection{Deporte y Derecho Internacional de los Derechos Humanos}

Rara vez se han ocupado los órganos del sistema de protección de NNUU de la compatibilidad con las obligaciones internacionales en materia de derechos humanos de comportamientos de los Estados relativos a cuestiones relacionadas con la actividad de organizaciones deportivas. Sí podemos, a pesar de ello, encontrar algunos pronunciamientos interesantes. Así, en sus Observaciones Finales al primer Informe periódico de China ${ }^{41}$, el Comité de derechos económicos, sociales y culturales se mostró preocupado por el número de desalojos forzosos y demoliciones producidos en China en anticipación de los Juegos Olímpicos de $2008^{42}$ y recomendó al Estado tomar las «medidas inmediatas para hacer cumplir las leyes y los reglamentos que prohíben el desalojo forzoso y velar por que se proporcione a las personas desalojadas de sus viviendas una indemnización adecuada o un alojamiento alternativo, de conformidad con las directrices aprobadas por el Comité y con su Observación general núm. 7 (1997), sobre el derecho a una vivienda adecuada (art. 11, párr. 1 del Pacto): los desalojos forzosos» ${ }^{43}$.

La reflexión sobre las relaciones entre el deporte y el DIDH puede hacerse desde un triple punto de vista. En primer lugar, merece la pena analizar si el deporte se ha configurado como un instrumento útil para la promoción de los derechos humanos. Cabría preguntarse, en segundo lugar, si se habría codificado, en el plano internacional, un derecho individual al deporte. Debe examinarse, por último, la cuestión de la protección de los derechos de los deportistas cuando la eventual vulneración de los mismos deriva de la aplicación de normas o procedimientos deportivos. Esto es, diseñados e implementados en dicho entorno. Con este último propósito, se prestará atención a la protección de los menores deportistas, de un lado, y a la cuestión de la violación de los derechos de los deportistas en el ámbito de la lucha contra el dopaje, de otro ${ }^{44}$.

41 E/C.12/1/Add.107, de 13 de mayo de 2005, disponible en http://tbinternet.ohchr.org/_layouts/treatybodyexternal/TBSearch.asp $x$ ? Lang=en\&TreatyID=9\&DocTypeID=5.

42 Véase el apartado 31 de las Observaciones Finales.

43 Ibid., apartado 61. Lo cierto es que representantes de la sociedad civil y determinados analistas vienen denunciando desde hace tiempo abusos de derechos humanos asociados a la celebración de grandes eventos deportivos (entre ellos, el aumento de la trata de seres humanos y de la explotación, incluida la explotación de menores, los desplazamientos forzosos como los que preocupan al Comité en este caso, o el aumento de la violencia de los cuerpos y fuerzas de seguridad del Estado). Sirven de ejemplo reciente de esta idea las denuncias sobre violaciones de derechos humanos de los trabajadores cometidas con ocasión de la preparación del Campeonato Mundial de Fútbol de Catar: https://www.amnesty.org/es/latest/news/2016/03/abuse-of-world-cup-workers-exposed/. Por otro lado, el Informe titulado «Striving for Excellence: Mega-Sporting Events and Human Rights» publicado en 2013 por el «Institute for Human Rights and Business» contiene algunas recomendaciones interesantes al respecto, entre ellas el establecimiento de una suerte de Ombudsman que, bajo la autoridad de los organismos deportivos, asuma la facultad de recibir quejas sobre violaciones de derechos humanos cometidas con ocasión de la celebración de grandes eventos deportivos. Este Informe está disponible en $h t t p: / / w w w$. ihrb.org/pdf/2013-10-21_IHRB_Mega-Sporting-Events-Paper_Web.pdf.

44 Además, no puede dejar de mencionarse aquí la Convención internacional contra el apartheid en los deportes, aprobada por la AGNU mediante su Resolución A/RES/40/64, de 10 de diciembre de 1985, 


\subsubsection{Deporte y promoción de los derechos humanos}

Cabe señalar, de modo necesariamente breve, que el innegable atractivo del deporte ha servido para que diferentes Organizaciones y Organismos internacionales hayan recurrido a él para implementar estrategias de promoción de los derechos humanos y de prevención de sus violaciones ${ }^{45}$. Es el caso de algunas acciones implementadas por el Fondo de las Naciones Unidas para la Infancia (UNICEF) ${ }^{46}$ o el Alto Comisionado de las Naciones Unidas para los Refugiados (ACNUR) ${ }^{47}$.

Este vínculo entre deporte y promoción de los derechos humanos ha sido, por lo demás, explícitamente reivindicado. Así, en 2011, el Consejo de Derechos Humanos adoptó una resolución en la que instaba a la promoción del conocimiento, la comprensión y la aplicación de la Declaración Universal de Derechos Humanos mediante el deporte y el ideal olímpico ${ }^{48}$.

\subsection{2. ¿Un derecho humano al deporte?}

Los órganos de protección internacional de derechos humanos han abordado la configuración de un derecho humano a la práctica del deporte desde distintos ángulos. Se ha concebido, tal y como se analizará enseguida, como parte del derecho a la educación, sobre todo de los menores. También como parte del derecho a la salud. Cabe citar en este último sentido la Resolución del Consejo de Derechos Humanos 26/18, de 14 de julio de 2014, sobre «El derecho de toda persona al disfrute del más alto nivel posible de salud física y mental: el deporte y los estilos de vida saludables como factores coadyuvantes» ${ }^{49}$. Además, determinados tratados de derechos humanos aprobados en el seno de NNUU, aquellos que tratan de proteger frente a la discriminación en el goce de sus derechos a ciertos grupos vulnerables, han incluido entre las medidas que deben ser adoptadas por sus Estados parte las encaminadas a evitar la discriminación en el acceso y la práctica del deporte y la actividad física.

Es el caso, por ejemplo, de las mujeres. El Comité de Derechos Humanos observó en 1993, con ocasión de la presentación del segundo Informe periódico de Irán, que «la persistencia y la importancia de las discriminaciones contra la mujer son incompatibles con las disposiciones del artículo 3 del

\footnotetext{
disponible en https://documents-dds-ny.un.org/doc/RESOLUTION/GEN/NR0/485/51/IMG/NR048551. pdf? OpenElement.

${ }^{45}$ Kirchschlaeger, P. G., «Sports and Human Rights from an Ethical Perspective: The Relevance of Human Rights for Sports", en Akrivopoulou, Ch. (ed.), Defending Human Rights and Democracy in the Era of Globalization, Hershey, IGI Global, 2017, pp. 337-360.

46 Para una reflexión sobre el modo en que el deporte puede servir a sus propósitos, puede consultarse el siguiente enlace: $h t t p: / / w w w . u n i c e f . o r g / s p a n i s h / s p o r t s / 23619 \_57597 . h t m l$.

47 Sirven de ejemplo los proyectos de los que se da cuenta en el siguiente enlace: $h t t p: / / w w w . u n h c r$. org/pages/4a0d90946.html.

${ }_{48}$ Se trata de la Resolución 18/23, de 28 de septiembre de 2011 (A/HRC/18/L.18/Rev.1). Está disponible en http://ap.ohchr.org/documents/dpage_e.aspx?si=A/HRC/18/L.18/Rev.1.

49 Disponible en http://www.ohchrorg/EN/Issues/Health/Pages/OverviewMandate.aspx.
} 
Pacto» y señaló entre esas discriminaciones la prohibición de la práctica de deportes en público ${ }^{50}$.

Por su parte, el art. 10.g) de la Convención para la eliminación de todas las formas de discriminación contra la mujer ${ }^{51}$ establece la obligación de los Estados parte de adoptar «todas las medidas apropiadas para eliminar la discriminación contra la mujer, a fin de asegurarle la igualdad de derechos con el hombre en la esfera de la educación y en particular para asegurar, en condiciones de igualdad entre hombres y mujeres», la participación activa en el deporte y en la actividad física. En el mismo sentido puede citarse el art. 13.c) de la Convención ${ }^{52}$.

Cabe también entender, en relación ahora con los menores, que los arts. 23.2 y 3 y 31 de Convención sobre los Derechos del Niño (CDN) ${ }^{53}$ incluyen el deporte entre las actividades recreativas y de esparcimiento a las que los menores tienen derecho ${ }^{54}$. Lo establece, ahora sí expresamente, respecto de los niños y niñas con discapacidad, el apartado 5 del art. 30 de la Convención sobre los derechos de las personas con discapacidad ${ }^{55}$. El artículo se refiere, precisamente, a la participación de las personas con discapacidad en la vida cultural, las actividades recreativas, el esparcimiento y el deporte. La Convención vincula de un modo explícito deporte y derecho a la educación. Su art. 29.1.a) afirma que los Estados parte convienen en que la educación del niño deberá estar encaminada a desarrollar su personalidad, sus aptitudes y su capacidad mental y física hasta el máximo de sus posibilidades ${ }^{56}$. Puede afirmarse, en ese sentido, que el derecho a la educación física forma parte del derecho a la educación, al menos de los menores, tal y como está concebido en el plano internacional ${ }^{57}$. En esa medida, y con el fin de garanti-

50 Véase el apartado 13 de las Observaciones Finales del Comité (CCPR/C/79/Add.25, de 3 de agosto de 1993), disponibles en http://tbinternet.ohchr.org/_layouts/treatybodyexternal/TBSearch.aspx? Lang= en\&Treaty $I D=8 \&$ DocType $I D=5$.

51 Aprobada el 18 de diciembre de 1979, BOE núm. 69, de 21 de marzo de 1964.

52 Sobre el papel del Comité para la eliminación de la discriminación contra la mujer, véase JoNES, K. L., «Women's national leagues: does CEDAW go far enough?», International Sports Law Journal, 2013, núm. 1, pp. 35-44.

53 Aprobada el 20 de noviembre de 1989, BOE núm. 313, de 31 de diciembre de 1990.

54 Así lo ha entendido, desde luego, el Comité de derechos del niño. Véanse, en este sentido, las Observaciones Finales al segundo Informe periódico de Portugal (CRC/C/15/Add.162, de 6 de noviembre de 2001), en las que el Comité advierte de que las actividades deportivas reciben un apoyo financiero insuficiente por parte del Estado y de que este debe tomar medidas para que el número de niños que participan en las mismas aumente (apdo. 44). Las Observaciones Finales están disponibles en http:// tbinternet.ohchr.org/_layouts/treatybodyexternal/TBSearch.aspx? Lang=en\&TreatyID=5\&TreatyID=10\&Tre atyID=11\&DocTypeID $=5$.

55 Aprobada el 13 de diciembre de 2006, BOE núm. 96, de 21 de abril de 2008. A las obligaciones de los Estados (en este caso, parte en la CDN) respecto del acceso a la actividad deportiva de los niños con discapacidad se refiere también el apartado 72 de la Observación General núm. 9 (2006) del Comité de derechos del niño relativa a esta cuestión (CRC/C/GC/9, de 27 de febrero de 2007), disponible en http://tbinternet.ohchr.org/_layouts/treatybodyexternal/Download.asp $x$ ?symbolno $=C R C \% 2 f C \% 2 f G C \% 2 f 9 \& L a n g=e n$.

56 La cursiva es mía.

57 Sobre el derecho a la educación física y a participar en actividades deportivas, véase KIDD, B. y Donnelly, P., «Human Rights in Sports», International Review for the Sociology of Sport, vol. 35, 2000, núm. 2, pp. 131-148. La Resolución de la AGNU 58/5, ya citada aquí, asume con claridad dicha rela- 
zar el disfrute de ese derecho, se impone a los Estados la obligación de incluir la educación física en los sucesivos itinerarios educativos y de garantizar la igualdad de condiciones en el acceso a la misma.

La falta de acceso o el acceso insuficiente a la actividad física y/o deportiva pueden considerarse, en determinadas circunstancias, trato inhumano o degradante. Así lo han entendido en algunos casos tanto los órganos de protección de derechos humanos del sistema de NNUU ${ }^{58}$, como los del Consejo de Europa ${ }^{59}$.

Más allá de eso, ninguna norma convencional protege de modo autónomo el derecho al deporte. Sí se ha recogido esa pretensión en normas de soft law. El 21 de noviembre de 1978 UNESCO adoptó la denominada Carta internacional de la educación física y el deporte, cuya versión revisada fue aprobada el 17 de noviembre de $2015^{60}$. Su artículo primero declara el derecho fundamental de todo individuo a acceder a la educación física, la actividad física y al deporte, que se consideran «esenciales para el pleno desarrollo de la personalidad en sus dimensiones física, intelectual y moral». Estas consideraciones son coherentes con lo establecido al respecto en el Pacto Internacional de Derechos Económicos, Sociales y Culturales (PIDESC) ${ }^{61}$ y, en lo que hace a los menores, en la ya citada CDN. Con todo, la Carta internacional de la UNESCO de la educación física y el deporte es el instrumento internacional que más claramente se ha referido a esta vinculación. Como se ha dicho, la Carta configura la práctica de la educación física y el deporte como un derecho fundamental. Y, en consonancia con esta idea, trata de orientar la acción de los Estados. Considera, en particular que la educación física y el deporte deben constituir elementos esenciales de la educación permanente dentro del sistema global de educación. Los Estados deberían, por tanto, asegurar la práctica del deporte y la educación física a la hora de diseñar sus planes educativos ${ }^{62}$.

ción. Su apartado 1.e), por ejemplo, insta a «seguir promoviendo el deporte y la educación física [...] como instrumento de [...] educación» y el 1.f) a «fortalecer la cooperación y la asociación entre todos los agentes, incluidos la familia, la escuela, los clubes y ligas, las comunidades locales, las asociaciones deportivas juveniles y los responsables de tomar decisiones, así como el sector público y el privado, para asegurar la complementariedad y lograr que el deporte y la educación física estén al alcance de todos».

58 Así lo ha mantenido, por ejemplo, el Comité contra la tortura en sus Observaciones Finales al tercer Informe periódico presentado por Bulgaria (CAT/C/CR/32/6) adoptadas el 11 de junio de 2004, disponibles en http://tbinternet.ohchr.org/_layouts/treatybodyexternal/TBSearch.aspx? Lang=en\&TreatyID $=1 \&$ DocTypeID=5 [apdo. 5.h)].

59 El Comité europeo para la prevención de la tortura ha afirmado reiteradamente que las personas privadas de libertad deben tener acceso diario a la práctica de actividad física o de algún deporte. Véanse, por ejemplo, sus Estándares sobre las condiciones que deben cumplir los establecimientos penitenciarios [CPT/Inf (2015) 44] adoptados el 15 de diciembre de 2015 y disponibles en http://www. cpt.coe.int/en/working-documents/cpt-inf-2015-44-eng.pdf.

${ }^{60}$ Véase supra, nota 6. Se denomina desde entonces «Carta Internacional de la educación física, la actividad física y el deporte».

${ }_{61}$ Adoptado por la AGNU mediante su Resolución 2200 A (XXI), de 16 de diciembre de 1966, BOE núm. 103, de 30 de abril de 1977.

${ }_{62}$ Cfr. el art. 2 de la Carta. En el ámbito europeo, la Carta Europea del Deporte, aprobada en 1992, también señala la necesidad de favorecer el acceso de los jóvenes al ejercicio de la actividad deportiva. 
Aun careciendo de fuerza jurídica vinculante, las declaraciones de la Conferencia General de la UNESCO recogen principios y objetivos a cuya puesta en práctica y consecución las partes se comprometen por considerarlos de particular relevancia. Tampoco son formalmente vinculantes ni el documento final del periodo extraordinario de sesiones de la AGNU sobre la infancia, aprobado el 10 de mayo de 200263, ni el denominado «Marco de Acción de Dakar» aprobado con ocasión del Foro Mundial sobre la Educación, celebrado entre el 26 y el 28 de abril de $2000^{64}$. Ambos subrayan las importantes funciones que están llamados a cumplir el deporte y la educación física y junto con los instrumentos mencionados podrían considerarse prueba de una cierta opinio iuris en este ámbito ${ }^{65}$.

\subsubsection{La protección de los derechos humanos de los deportistas}

\section{a) La protección de los derechos de los menores deportistas}

La que fuera Alta Comisionada de NNUU para los Derechos Humanos subrayó hace unos años su preocupación por el hecho de que el deporte de competición siguiese siendo una de las pocas áreas donde no había calado aún, de manera adecuada, el valor por el respeto de las normas y estándares internacionales de protección de los derechos de los niños ${ }^{66}$. En el año 2003, y creo que sus preocupaciones siguen siendo de plena actualidad, la AGNU puso el acento en algunos de los «desafíos» a los que la Comunidad Internacional se enfrenta en este ámbito ${ }^{67}$. La resolución cita como principales preocupaciones el trabajo infantil ${ }^{68}$, la violencia, el dopaje, la especialización temprana,

\footnotetext{
Se aprobó mediante la recomendación del Consejo de Ministros del Consejo de Europa R (92) 13, de 24 de septiembre de 1992, disponible en $h t t p: / / w w w . c o e . i n t / t / d g 4 / e p a s / r e s o u r c e s / c h a r t e r \_e n . a s p . ~ L a$ Carta fue revisada en 2001 y tiene un antecedente: la "Carta Europea sobre el Deporte para todos», adoptada por los ministros europeos del deporte el 24 de septiembre de 1976.

63 El documento, titulado «Un mundo apropiado para los niños», está disponible en $h t t p: / / w w w$. unicef.org/spanish/specialsession/docs_new.

${ }_{64}$ Disponible en http://unesdoc.unesco.org/images/0012/001211/121147s.pdf.

65 La Comisión de Derecho Internacional incluye entre los materiales útiles para determinar el elemento subjetivo a efectos de definir una norma de Derecho internacional consuetudinario la posición de los Estados ante Organizaciones o Conferencias internacionales. Véase, al respecto, el «Memorando de la Secretaria sobre formación y documentación del Derecho internacional consuetudinario. Elementos de la labor realizada anteriormente por la Comisión de Derecho Internacional que podrían ser de particular interés para el tema», de 14 de marzo de 2013 (A/CN.4/659), disponible en http://www. un.org/ga/search/viewm_doc.asp? symbol=A/CN.4/659.

${ }_{66}$ Véase su prólogo a la obra de DAvid, P., Human rights in youth sport: A critical review of children's rights in competitive sports, Nueva York, Abingdon, 2005, p. viii.

67 Cfr. el preámbulo de la Resolución $58 / 5$, ya citada aquí.

68 El Comité de derechos del niño se ha hecho eco en algunas ocasiones de esta preocupación. Así, por ejemplo, en sus Observaciones Finales al Informe inicial de Omán (CRC/C/15/Add.161, de 6 de noviembre de 2001), se mostró «preocupado por la peligrosa situación de los niños que participan en las carreras de camellos. En particular le preocupa que a veces se haga participar a niños muy pequeños y que, a consecuencia de ello, estos sufran lesiones graves e incluso mortales»: véase el apartado 51 de las Observaciones Finales, disponibles en http://tbinternet.ohchr.org/_layouts/treatybodyexternal/Download.aspx? symbolno $=C R C \% 2 f C \% 2 f 15 \% 2 f A d d .161 \& L a n g=e n$. Mostró la misma preocupación, en rela-
} 
el exceso de entrenamiento y las formas de comercialización que constituyen explotación ${ }^{69}$, así como las amenazas y privaciones menos visibles, entre las que se encontrarían la ruptura prematura de los lazos familiares y la pérdida de vínculos deportivos, sociales y culturales ${ }^{70}$.

\section{b) La protección en el ámbito de la lucha contra el dopaje en el deporte}

La cooperación entre los diversos actores implicados ha sido siempre indispensable para asegurar la efectividad en la lucha contra el dopaje. Siendo esto así, cualquier entramado internacional creado con tal fin debía tener en cuenta la diversa naturaleza jurídica, pública y privada, de esos actores. La creación de la Agencia Mundial Antidopaje (AMA) demostró precisamente eso: que la armonización normativa y la coordinación entre autoridades públicas y privadas resultan ser elementos clave de la lucha internacional contra el dopaje ${ }^{71}$. Se trata, desde el punto de vista jurídico, de una fundación de Derecho privado regulada por sus Estatutos y por los arts. 80 y ss. del Código Civil suizo. Desde un punto de vista organizativo, la AMA constituye

ción con el mismo problema, en las Observaciones Finales al Informe inicial de los Emiratos Árabes Unidos (CRC/C/15/Add.183, de 13 de junio de 2002, apdo. 40), disponibles en http://tbinternet.ohchr. org/_layouts/treatybodyexternal/Download.aspx?symbolno=CRC\%2fC\%2f15\%2fAdd.183\&Lang=en. En un sentido similar, el Comité alertó expresamente en sus Observaciones Finales al segundo Informe periódico de Mongolia sobre «la peligrosa situación de los niños que, con cada vez mayor frecuencia, participan y son explotados en carreras tradicionales de caballos, carreras que han experimentado cambios considerables y han pasado de ser un deporte tradicional a ser un negocio lucrativo en el que se abusa de los niños y se los explota» (CRC/C/15/Add.264, de 21 de septiembre de 2005, apdo. 60). Estas Observaciones Finales están disponibles en http://tbinternet.ohchr.org/_layouts/treatybodyexternal/ TBSearch.asp $x$ ? Lang=en\&TreatyID $=5 \&$ Treaty $I D=10 \&$ Treaty $I D=11 \&$ DocType $I D=5$.

${ }^{69}$ La explotación de los jóvenes jugadores se identifica también como uno de los retos o amenazas a las que se enfrenta actualmente el deporte en el Libro Blanco de la Comisión Europea sobre el deporte [COM (2007) 391 final], disponible en http://europa.eu/legislation_summaries/education_training_youth/sport/l35010_es.htm.

70 Véase el preámbulo de la Resolución 58/5 de la AGNU.

71 Debido a los crecientes escándalos de dopaje, y en particular los acaecidos con ocasión del Tour de Francia de 1998, el COI convocó una Conferencia Mundial sobre el dopaje en el deporte que se celebró en Lausana en febrero de 1999. La Declaración sobre el Dopaje en el Deporte aprobada en el marco de la Conferencia proponía la creación de un organismo internacional antidopaje independiente. El texto de la declaración está disponible en https://wcd.coe.int/ViewDoc.jsp?id=402791. Siguiendo esta indicación, la AMA fue creada en noviembre de 1999 para coordinar la lucha contra el dopaje en el deporte en el ámbito internacional. Esta estructura se encuentra actualmente en proceso de revisión. Durante la 5. ${ }^{\text {a }}$ Cumbre Olímpica celebrada el 5 de octubre de 2016 en Lausana, el COI acordó proponer modificaciones sustanciales al sistema mundial de control de dopaje. Con ese propósito, y de acuerdo con lo indicado en la Agenda Olímpica 2020, que se adoptó en diciembre de 2014, aprobó una Declaración en la que se detallan los propósitos y líneas básicas de la propuesta del COI. Entre ellas, lograr un sistema de control de dopaje más independiente de las organizaciones deportivas (para lo que se debería crear una nueva autoridad de control del dopaje en el seno de la AMA y debería otorgarse al CAS la competencia para imponer las sanciones) y de los intereses nacionales (para ello, la AMA debería tener mayor autoridad sobre las Organizaciones Nacionales Antidopaje y debería poder supervisar los programas nacionales antidopaje). Parece evidente que en el centro de las preocupaciones del COI se encuentra el reciente escándalo de dopaje protagonizado por Rusia, que tuvo efectos devastadores para la participación de sus atletas en los Juegos Olímpicos de Río de Janeiro. La declaración del COI se encuentra disponible en https://www.olympic.org/news/declaration-of-the-5th-olympic-summit. 
un modelo sui generis que ha sido considerado un ejemplo paradigmático «de la emergencia de las nuevas formas de mecanismos híbridos de gobernanza público-privados en la esfera global ${ }^{72}$ y una muestra del compromiso de actores públicos y privados en el ejercicio conjunto de una determinada función ${ }^{73}$.

La AMA ha generado un corpus iuris, el Programa Mundial Antidopaje, compuesto por tres elementos: el Código Mundial Antidopaje (el Código AMA $)^{74}$, los Estándares Internacionales y el Modelo de Buenas Prácticas ${ }^{75}$.

El Código AMA puede ser considerado el documento clave del Programa Mundial Antidopaje. Su propósito principal es armonizar las políticas y reglas que en materia de lucha contra el dopaje se han adoptado por parte de las organizaciones deportivas y autoridades públicas en el mundo. Junto al Código AMA, se han aprobado cinco Estándares Internacionales que pretenden armonizar y clarificar diversos aspectos en el ámbito de la lucha contra el dopaje ${ }^{76}$. Lo que interesa poner de manifiesto ahora es que algunas de las normas contenidas en esta normativa de la AMA podrían vulnerar determinados estándares internacionales de protección de derechos humanos. Es el caso de lo requerido por la Agencia a los deportistas en relación con el deber de estar localizados para someterse a controles antidopaje ${ }^{77}$.

72 CAsInI, L., "Global Hybrid Public-Private Bodies: The World Anti-Doping Agency (WADA)», International Organizations Law Review, vol. 5, 2009, núm. 2, p. 424.

73 Chiti, E., "The Governance of Compliance», en Cremona, M. (ed.), Compliance and the Enforcement of EU Law, Oxford, Oxford University Press, 2012, p. 45.

74 Véase sobre el mismo: DavID, P., A Guide to the World Anti-Doping Code: The Fight for the Spirit of Sport, 2. ${ }^{\text {a }}$ ed., Cambridge, Cambridge University Press, 2013.

75 Todos estos instrumentos fueron modificados durante la III Conferencia Mundial sobre Dopaje en el Deporte celebrada en Johannesburgo en noviembre de 2013. Las modificaciones allí aprobadas entraron en vigor el 1 de enero de 2015. Todos los instrumentos citados en esta parte del trabajo están disponibles en https://www.wada-ama.org/en/what-we-do/the-code/2015-world-anti-doping-codeimplementation.

76 La Lista de Sustancias y Métodos Prohibidos, el Estándar Internacional sobre Controles, el Estándar Internacional sobre Laboratorios, el Estándar Internacional sobre Autorización de Uso Terapéutico y el Estándar Internacional para la Protección de la Intimidad y la Información Personal.

77 Véanse al respecto los trabajos de: BYrnes, A., op. cit., nota 17, pp. 81-104; Conolly, R., «Balancing the Justices in Anti-Doping Law: The Need to Ensure Fair Athletic Competition Through Effective Anti-Doping Programs v. the Protection of Rights of Accused Athletes», Virginia Sports and Entertainment Law Journal, vol. 5, 2006, núm. 2, pp. 41-80; HALT, J., "Where is the Privacy in WADAS's "Whereabouts" Rule?», Marquette Sports Law Review, vol. 20, 2001, núm. 1, pp. 267-281; HanSTAD, D. V. y LOLAND, S., "Elite athletes' duty to provide information on their whereabouts: Justifiable anti-doping work or an indefensible surveillance regime?», European Journal of Sport Science, vol. 9, 2009, núm. 1, pp. 3-10; Hard, M., "Caught in the Net: Athletes' Rights and the World Anti-doping Agency», Southern California Interdisciplinary Law Journal, vol. 19, 2010, pp. 533-564; HouliHAN, B., «Civil Rights, Doping Control and the World Anti-doping Code», Sport in Society, vol. 7, 2004, núm. 3, pp. 420-437; LuKomSKI, J., «Arbitration clauses in sport governing bodies' statutes: consent or constraint? Analysis from the perspective of Article 6(1) of the European Convention on Human Rights", International Sports Law Journal, 2013, núm. 1, pp. 60-70; MACGREGOR, O., et al., "Anti-doping, purported rights to privacy and WADA's whereabouts requirements: A legal analysis», Fair Play. Revista de Filosofía, Ética y Derecho del Deporte, vol. 1, 2013, núm. 2, disponible en http://www.upf.edu/revistafairplay/anteriores/; y SoEK, J.-W., "The Fundamental Rights of Athletes in Doping Trials», en O'LearY, J. (ed.), Drugs and Doping in Sport: Socio-Legal Perspectives, Londres, Cavendish, 2001, pp. 57-73. 
El Código AMA, en su art. 2.4, tipifica como infracción a las normas antidopaje «el incumplimiento de la localización/paradero del deportista». Dicha infracción consistirá en «(c)ualquier combinación de tres controles fallidos y/o de incumplimientos del deber de proporcionar los datos de localización/ paradero, como está definido en el Estándar Internacional para Controles e Investigaciones, dentro de un periodo de doce meses, por un Deportista del Grupo Registrado de Control». El art. 10 del Código establece en su apartado 3.2 cuál será la sanción por la comisión de una de las infracciones previstas en el mencionado art. 2.4: la suspensión por un periodo que irá del año a los dos años, dependiendo del grado de culpabilidad del deportista.

El Estándar Internacional sobre Controles e Investigaciones ${ }^{78}$ especifica detalladamente en su Anexo I las obligaciones de los deportistas sujetos a control, esto es, aquellos que forman parte de un Grupo Registrado de Control $^{79}$. En el mismo se precisa tanto la información que debe ser proporcionada por el atleta ${ }^{80}$ como el momento en el que debe ser proporcionada ${ }^{81}$. Además, dicha información «deberá incluir, por cada día del siguiente trimestre, un intervalo de tiempo específico de 60 minutos entre las 5 a.m. y las 11 p.m. cada día en el que el [d]eportista estará disponible y podrá ser ubicado» para la realización de los controles en un lugar específico ${ }^{82}$.

Se impone al deportista la obligación «de asegurarse de proporcionar toda la información requerida [...] de forma exacta y lo suficientemente detallada como para permitir que cualquier Organización Antidopaje pueda localizarlo con el fin de realizar los controles cualquier día del trimestre en los horarios y lugares especificados» ${ }^{83}$, incluido el intervalo de tiempo de sesenta minu-

78 Me refiero aquí a la versión en vigor desde enero de 2015, disponible en https://wada-main-prod. s3.amazonaws.com/resources/files/wada-2015-isti-final-esp_0.pdf. Una nueva versión estará en vigor desde el 1 de enero de 2017. Dicha versión está disponible en https://wada-main-prod.s3.amazonaws. com/resources/files/isti_2017_jan_spanishfinal.pdf.

79 Que el Estándar Internacional sobre Controles e Investigaciones define como el «Grupo de deportistas de la más alta prioridad identificados separadamente a nivel internacional por las Federaciones Internacionales y a nivel nacional por las Organizaciones Nacionales Antidopaje, que están sujetos a la vez a controles específicos en competición y fuera de competición en el marco de la planificación de distribución de los controles de dicha Federación Internacional u Organización Nacional Antidopaje y que están obligados a proporcionar información acerca de su localización/paradero conforme al art. 5.6 y el Estándar Internacional para Controles e Investigaciones».

${ }^{80}$ Entre la información requerida se encuentra una dirección postal completa donde se le pueda enviar correspondencia, la dirección completa del lugar donde pasará la noche (su casa, un alojamiento temporal, un hotel, etc.), el nombre y la dirección de cada lugar donde entrenará, trabajará o realizará cualquier otra actividad regular y los periodos de tiempo habituales en los que realiza esas actividades regulares y el programa de competición (que incluirá el nombre y dirección de cada lugar donde el deportista tiene programado competir durante el trimestre y las fechas en las que tiene programado competir en dichos lugares).

81 La información se proporcionará, por cada día del siguiente trimestre, en una fecha especificada por la Organización Antidopaje Responsable. Esta fecha será anterior al primer día de cada trimestre (1 de enero, 1 de abril, 1 de julio y 1 de octubre).

82 Por supuesto, si cambian las circunstancias y el deportista no va a estar disponible en el lugar especificado cuando proporcionó la información, podrá actualizarla.

83 Véanse las «Directrices para la implementación de un Programa de Controles eficaz» aprobadas por la AMA y disponibles en https://wada-main-prod.s3.amazonaws.com/resources/files/wada_guidelines_effective_testing_2014_spa.pdf. 
tos al que se ha hecho referencia. Dicha información deberá ser suficiente para que la Organización Antidopaje pueda encontrar el lugar especificado, acceder al mismo y encontrar al deportista. De no ser así, los hechos podrían calificarse como un incumplimiento del deber de proporcionar los datos de localización/paradero y/o como la evasión de una recogida de muestras, lo que llevará aparejada, en su caso, la sanción correspondiente. De acuerdo con las mencionadas «Directrices para la implementación de un Programa de Controles efectivo», el principio básico es el de la responsabilidad del propio deportista para lograr estar disponible para la realización de controles.

Las organizaciones y autoridades deportivas están obligadas por las reglas descritas en el epígrafe anterior. Las decisiones que adopten en aplicación de las mismas tendrán, además, un efecto directo sobre los deportistas, que podrán verse apartados de las competiciones ${ }^{84}$ durante largos periodos de tiempo ${ }^{85}$.

Así las cosas, ¿cuál es el papel que corresponde a los Estados? ¿Tienen la obligación de implementar lo requerido en el Código AMA y los Estándares Internacionales? Dar respuesta a estas preguntas exige analizar de qué modo el Código AMA y la Convención internacional de la UNESCO contra el dopaje en el deporte conciben sus relaciones mutuas.

Encontramos una respuesta preliminar a estas cuestiones en el art. 3 de la Convención, que establece que con el propósito de dar cumplimiento a los objetivos de la misma los Estados parte se obligan a adoptar medidas apropiadas, en el plano nacional e internacional, acordes con los principios del Código $^{86}$. Más explícito es el art. 4, que regula, precisamente, las relaciones de la misma con el Código AMA $^{87}$. De acuerdo con el apartado 3 del artículo,

84 Estas están, por lo demás, organizadas en términos de monopolio, lo que incide directamente en la supuesta «libertad» del deportista de federarse o no. Esto es, al igual que en el ámbito interno una única federación puede organizar competiciones oficiales, dicha facultad corresponderá, en el ámbito internacional, a una única Federación internacional o, en su caso, al COI. La cuestión de la eventual incompatibilidad de ese régimen de monopolio con las normas del Derecho de la competencia de la UE le fue sometida al Tribunal de Justicia en el asunto David Meca Medina e Igor Majcen c. Comisión de las Comunidades Europeas (asunto C-519/04-P, ECLI:EU:C:2006:492). El Tribunal afirmó que los recurrentes tenían razones fundadas para sostener que el Tribunal de Primera Instancia había incurrido en un error al desestimar su demanda basándose en que la normativa antidopaje controvertida (el Código antidopaje del COI aplicado por la Federación Internacional de Natación a los recurrentes) no estaba comprendida en el art. 49 del Tratado de la Comunidad Europea (actual art. 56 del TFUE) ni en el Derecho sobre la competencia (cfr. el apdo. 34 de la sentencia). Véase sobre esta sentencia: ZYLBERSTEIN, J., "Collision entre idéaux sportifs et contingences économiques dans l'arrêt Meca-Medina», Cahiers du Droit Européen, vol. 43, 2002, núms. 1-2, pp. 213-237. Y sobre la cuestión de la aplicación del Derecho de la competencia de la UE en este ámbito: VAN RoMPUY, B., "The role of EU competition law in tackling abuse of regulatory power by sports associations», Maastricht Journal of European and Comparative Law, vol. 22, 2015, núm. 2, pp. 179-208.

85 "Quant à la force de coercition des ordres juridiques sportifs, elle prend la forme de l'exclusion (analogue à l'excommunication du droit canonique), laquelle est souvent plus efficace que les actes matériels de contrainte physique appliqués par l'État sur son territoire, mais dont la force s'éteint au-delà de ses frontières», RigauX, F., op. cit., nota 2, p. 66.

${ }^{86}$ La cursiva es mía.

87 En virtud del apartado primero de este artículo, «(c)on miras a coordinar, en el plano nacional e internacional, las actividades de lucha contra el dopaje en el deporte, los Estados Parte se comprome- 
solo los Anexos I ${ }^{88}$ y II ${ }^{89}$ forman parte integrante de la Convención. El art. 4.2 establece que las versiones actualizadas de los Apéndices $2^{90}$ y $3^{91}$ solo se reproducen a título informativo y que no forman parte integrante de la misma. Dichos apéndices, añade, «no crean ninguna obligación vinculante en Derecho internacional para los Estados Parte».

Por otro lado, el art. 22 del Código AMA regula la «implicación de los gobiernos» en la implementación del Programa Antidopaje de la Agencia. Establece que con el objeto de hacer constar su compromiso con respecto al Código, cada gobierno «firmará» la Declaración de Copenhague contra el dopaje en el deporte de 3 de marzo de $2003^{92}$, y ratificará, aceptará, aprobará o asumirá la Convención de la UNESCO ${ }^{93}$.

Los distintos apartados del art. 22 establecen las «expectativas» que deben cumplir los signatarios. Entre ellas, emprender las acciones y tomar las medidas necesarias para dar cumplimiento a la Convención de la UNESCO (art. 22.1), promover la cooperación entre la totalidad de sus servicios o agencias públicas y las Organizaciones Antidopaje para que compartan con ellas información que pueda resultar útil en la lucha contra el dopaje, siempre y cuando con ello no se infrinja "ninguna otra norma jurídica» (art. 22.3), y respetar el arbitraje como vía preferente para resolver disputas relacionadas con el dopaje, «teniendo en cuenta los derechos humanos y fundamentales y el correspondiente Derecho nacional aplicable» (art. 22.4).

Siendo únicamente «expectativas», cabe preguntarse cuáles serían las consecuencias de que las mismas no fuesen satisfechas por los Gobiernos. El apartado 8 del art. 22 del Código AMA únicamente se refiere a la no ratificación, aceptación, aprobación o asunción de la Convención de la UNESCO antes del 1 de enero de 2016, o a su incumplimiento. En tales casos, el Estado podría no ser elegible para optar a la celebración de eventos deportivos. Además, el incumplimiento del Código por parte de los signatarios podrá

ten a respetar los principios del Código como base de las medidas previstas en el Art. 5 de la presente Convención. Nada en la presente Convención es óbice para que los Estados Parte adopten otras medidas que puedan complementar las del Código».

${ }_{88}^{8}$ La lista de sustancias prohibidas.

${ }^{89}$ Las normas para la concesión de autorizaciones para uso con fines terapéuticos.

${ }_{90}$ Las normas internacionales para los laboratorios.

${ }^{91}$ La norma internacional para los controles, a la que nos acabamos de referir.

92 Disponible en https://www.wada-ama.org/en/resources/world-anti-doping-program/copenhagendeclaration.

${ }_{93}$ Tal y como se explica en el comentario al art. 22 «(l)a mayor parte de los gobiernos no pueden ser partes de, ni quedar vinculados por, instrumentos privados no gubernamentales como el Código. Es por ello por lo que no se pide a los gobiernos que sean Signatarios del Código, sino que firmen la Declaración de Copenhague y ratifiquen, acepten, aprueben o asuman la Convención de la UNESCO. Aunque los mecanismos de aceptación pueden ser diferentes, todas las medidas que tengan como objetivo la lucha contra el dopaje a través de un programa coordinado y armonizado según lo reflejado en el Código, siguen constituyendo un esfuerzo común del movimiento deportivo y de los gobiernos. Este artículo establece lo que los Signatarios esperan claramente de los gobiernos. No obstante, se trata simplemente de "expectativas", puesto que los gobiernos solamente están "obligados" a acatar las exigencias de la Convención de la UNESCO». 
acarrear consecuencias adicionales. Entre ellas, «la prohibición de ocupar dependencias y puestos dentro de la AMA, la imposibilidad de optar o la no admisión de candidaturas para celebrar Eventos Internacionales en un país, la cancelación de Eventos Internacionales, consecuencias simbólicas y otras con arreglo a la Carta Olímpica» ${ }^{94}$.

Un considerable número de Estados, sin embargo, ha incorporado las reglas a las que hemos hecho referencia a sus Derechos internos. Una eventual exclusión de sus selecciones o equipos de las competiciones internacionales parece haber sido un poderoso incentivo para hacerlo. Los problemas surgen si consideramos que esta normativa puede vulnerar obligaciones exigibles a esos mismos Estados en virtud del DIDH. ¿Les impone este sector del Derecho internacional límites en el marco de la lucha contra el dopaje en el deporte?

Siguiendo las reglas adoptadas en el seno de la AMA, las autoridades disciplinarias correspondientes, nacionales o internacionales, podrán decidir la imposición de la sanción que corresponda al deportista que ha vulnerado la normativa antidopaje. De acuerdo con el Código AMA, esas sanciones deben adoptarse después de un «juicio justo» en el que se respeten plenamente las garantías procedimentales del deportista ${ }^{95}$. Llegados a este punto, la cuestión que me interesa abordar es la de la posible intervención de los órganos de protección internacional de derechos humanos en caso de que aquellas garantías se viesen vulneradas. El razonamiento que sigue a continuación se ciñe, por tanto, a los casos en los que el deportista es sancionado por la infracción de la normativa antidopaje de acuerdo con unos procedimientos que son susceptibles de vulnerar sus derechos a la intimidad ${ }^{96}$, al buen nombre o al trabajo, y presupone, dada la regla del agotamiento previo de los recursos internos, la

94 Véase el art. 23.6 del Código AMA. España fue declarada por la AMA, el 19 de marzo de 2016, país «no cumplidor» del Código AMA. Dicho cumplimiento exige la reforma de la Ley Orgánica 3/2013, de 20 de junio, de protección de la salud del deportista y lucha contra el dopaje en la actividad deportiva, $B O E$ núm. 148, de 21 de junio de 2013, con el objeto de introducir dos nuevas infracciones a la normativa antidopaje (complicidad y asociación prohibida), aumentar las sanciones aplicables en caso de dopaje intencionado, que deberán pasar de dos a cuatro años de suspensión, la modificación del plazo de prescripción de las infracciones de los ocho años contemplados en la mencionada Ley Orgánica a los diez previsto por el Código AMA y la completa adecuación de la normativa española a las reglas sobre localización del deportista que han sido descritas aquí. Como consecuencia de dicha declaración, el Laboratorio de Control de Dopaje de Madrid fue «desacreditado» en junio de 2016: https://www.wadaama.org/en/media/news/2016-06/wada-suspends-the-accreditation-of-the-madrid-laboratory.

95 Véase el art. 8 del Código, relativo al derecho a un juicio justo y a la notificación del Dictamen de audiencia. Hay quien defiende la posibilidad de renunciar voluntariamente a este derecho: DE MONTMOLlin, J. y Penstov, D. A., "Do Athletes Really Have the Right to a Fair Trial in "Non-analytical Positive" Doping Cases?», American Review of International Arbitration, vol. 22, 2011, núm. 2, pp. 206-208.

96 Se ha pronunciado reiteradamente al respecto el Grupo de la UE de protección de datos del art. 29, creado por la Directiva 95/46/CE, del Parlamento Europeo y del Consejo, de 24 de octubre, relativa a la protección de las personas físicas en lo que respecta al tratamiento de datos personales y a la libre circulación de estos datos, DO L núm. 281, de 23 de noviembre de 1995 . Puede verse sobre el particular, por ejemplo, su Dictamen 3/2008 sobre el proyecto de norma internacional del Código Mundial Antidopaje para la protección de la intimidad, de 1 de agosto de 2008, disponible en http://ec.europa.eu/ justice/policies/privacy/docs/wpdocs/2008/wp156_es.pdf. Ha expresado preocupaciones semejantes, en el ámbito del Consejo de Europa, el Comité Europeo ad hoc para la AMA (CAHAMA, por sus siglas en 
intervención previa de los tribunales del Estado. Si bien el modelo de revisión de las sanciones deportivas parece evolucionar hacia posiciones favorables a la intervención, al menos limitada ${ }^{97}$, de los jueces internos ${ }^{98}$, resulta más complicado que dicha condición pueda cumplirse cuando la sanción ha sido impuesta por los órganos disciplinarios deportivos internacionales ${ }^{99}$.

Existe ya un grupo de casos esperando a ser admitidos a trámite por el Tribunal Europeo de Derechos Humanos (TEDH) ${ }^{100}$. Vamos a referirnos a ellos, de modo necesariamente breve ${ }^{101}$.

inglés). Véase al respecto su análisis disponible en $h t t p: / / w w w . c o e . i n t / t / d g h l / s t a n d a r d s e t t i n g / d a t a p r o t e c-$ tion/tpd_documents/T-DO(2012)INF16_EN_data_protection.pdf.

${ }_{97}$ Que no alcanza, en general, a la revisión de la vulneración de lo que cabría denominar «las reglas del juego", definidas como "the rules of the particular sport, as well has the enforcement of these rules by the game officials»: McLaren, R. H., «The Court of Arbitration for Sport», en NAFZIGER, J. A. R. y Ross S. F. (eds.), Handbook of International Sports Law, Cheltenham, Edward Elgar, 2011, p. 43.

98 "Most national courts [...] would not let the private nature of the actors stand in the way of an assessment of the rules and proceedings in the light of principles of administrative law (preliminary hearing, motivation on decisions, transparency and legal security...) and fundamental human rights (independence of tribunal, presumption of innocence)》: VAN VAERENBERGH, A., op. cit., nota 20, p. 17.

${ }_{99}$ En España, el art. 33 de la Ley Orgánica 7/2006, de 21 de noviembre, de protección de la salud y de lucha contra el dopaje en el deporte, $B O E$ núm. 279, de 22 de noviembre de 2006, establecía que las sanciones impuestas por organizaciones internacionales, a las que estén adscritas las respectivas federaciones deportivas españolas, se aplicarían en España y producirían la suspensión de la licencia federativa y la inhabilitación para participar en competiciones oficiales. Ello salvo que el extinto Comité Español de Disciplina Deportiva (CEDD) declarase la sanción contraria al ordenamiento jurídico español. En este sentido, el art. 22.2 de la Ley incorporaba un mecanismo que permitía a los deportistas cuestionar ante el mencionado CEDD la compatibilidad de la sanción impuesta por una Federación internacional, o el propio TAS, con los principios que informan la potestad sancionadora pública. La decisión del CEDD agotaba la vía administrativa previa al contencioso. Algunas decisiones de Federaciones internacionales fueron declaradas incompatibles con los mencionados principios y, consiguientemente, inaplicables en España, en aplicación de este mecanismo. La Ley Orgánica 7/2006 se mantuvo en vigor hasta el 11 de julio de 2013. Su «sucesora», la Ley Orgánica 3/2013, ya citada aquí, no contiene un mecanismo semejante. Para otros ejemplos en los que un juez interno ha decidido la inaplicación en el territorio del Estado de sanciones decididas por órganos deportivos internacionales, véase VAN VAERENBERGH, A., op. cit., nota 20, pp. 19-20.

100 Aunque se refiere a una normativa que ya no está en vigor, no puede dejar de citarse aquí la reciente sentencia de nuestro Tribunal Supremo que anula parcialmente la resolución de la Presidencia del Consejo Superior de Deportes de 4 de febrero de 2013, por la que se aprobaba en formulario de localización de los deportistas (BOE núm. 40, de 15 de febrero de 2013). En su Sentencia de 28 de julio de 2016 (ECLI:ES:TS:2016:408) la Sala de lo Contencioso Administrativo hace las siguientes observaciones: «Ya se ha dicho que no está en cuestión la represión del dopaje deportivo. Otra cosa es el límite de lo tolerable para lograr ese objetivo de lo que se ha dado en denominar "buen orden deportivo". Es cierto que los controles en competición no son suficientes para garantizar una seguridad total que evite el fraude a la competición. Así se pasó en la evolución de las medidas antidopaje a la realización de controles fuera de competición. Ello va suponiendo un creciente grado de incidencia en la esfera de libertad e intimidad personales. La realización de los controles fuera de competición parece requerir contar con información sobre el paradero habitual de los deportistas; se impone por ello a estos últimos la obligación de declararlo. La posibilidad de que la identificación del lugar de residencia no asegure el éxito del encuentro hace que dicha obligación torne en una obligación de acudir a un lugar determinado a una hora determinada. Se asegura así la completa disponibilidad del deportista si las autoridades competentes deciden realizar el control. Ahora bien, si no todo vale para competir $-\mathrm{y}$ de eso no cabe duda - tampoco vale todo para controlar. La existencia de un marco legal internacional (así art. 5.2 del Pacto Internacional de Derechos Civiles y Políticos y arts. 5 y 8 del Convenio Europeo para la Protección de los Derechos Humanos y de las Libertades Fundamentales) claramente consolidado en lo que hace al reconocimiento del derecho a la libertad personal y a la intimidad, exige que las 
De un lado, en dos casos que han sido hace ya algún tiempo comunicados a las partes y respecto de los que está pendiente una decisión sobre la admisibilidad, los demandantes cuestionan la compatibilidad de las medidas legislativas nacionales adoptadas para incorporar al ordenamiento jurídico interno las reglas contenidas en el Código AMA y los Estándares Internacionales con el Convenio Europeo de Derechos Humanos(CEDH) ${ }^{102}$. En abril de 2010, Francia adoptó la Ordenanza núm. 2010-379, relativa a la salud de los deportistas y a la adecuación del Código del Deporte con los principios del CMA. Dos años más tarde, se aprobó la Ley núm. 2012-158, relativa al refuerzo de la ética deportiva y de los derechos de los deportistas. Los demandantes en estos casos consideran que las exigencias relativas a la localización de los deportistas a los efectos de su sometimiento a los controles antidopaje contenidas en dicha normativa, que «traslada» al ordenamiento jurídico interno las exigencias del CMA, vulneran su derecho al respeto a la vida privada y familiar, garantizado por el art. 8.1 del CEDH, y el art. 2 del Protocolo núm. 4 al Convenio, que protege la libertad de circulación ${ }^{103}$. De otro lado, en otros tres asuntos que se encuentran también pendientes de una decisión sobre su admisibilidad, los demandantes consideran que el procedimiento ante el CAS vulnera el derecho a un proceso equitativo protegido por el art. 6 del $\mathrm{CEDH}^{104}$. La aplicación del mismo en el marco de los procedimientos que se

restricciones a estos derechos deberán estar previstas en un instrumento normativo de rango suficiente y, además, deberán ser interpretadas de una forma restrictiva» (FJ 7).

${ }_{101}$ En un sentido diferente, debe ponerse de manifiesto que el Tribunal de Justicia de la UE (TJUE) ha declarado inaplicables ciertas reglas deportivas que ha considerado contrarias al Derecho de la UE. El Tribunal de Luxemburgo ha afirmado reiteradamente, en lo que ya puede ser considerada una doctrina bien asentada, que el Derecho de la UE se aplica a la actividad deportiva en la medida en que la misma constituya una actividad económica. En otras palabras, la actividad deportiva caerá bajo el ámbito de aplicación del Derecho de la UE (de las libertades comunitarias y las normas sobre libre competencia) únicamente cuando su desempeño resulte en una actividad económica de algún modo regulada por aquel ordenamiento jurídico. Y, en consecuencia, únicamente será posible admitir aquellas excepciones que resulten justificadas por la necesaria consecución de otros fines del Derecho de la UE. Como, por ejemplo, la protección de la salud pública o la promoción de valores educativos. En esta misma línea, el TJUE ha mantenido que las normas deportivas no estarán sujetas al Derecho de la UE cuando regulen cuestiones que tengan un mero interés deportivo. Es el caso, entre otras reglas, de la que exige que los participantes en las selecciones nacionales tengan la nacionalidad del Estado al que el equipo representa. Para un análisis de las decisiones del TJUE relativas a la aplicación del Derecho de la UE a la actividad deportiva puede verse: Duval, A. y van Rompuy. B. (eds.), The Legacy of Bosman: Revisiting the Relationship between EU Law and Sport, La Haya, T. M. C. Asser Press, 2016, y PenN, D. W., «From Bosman to Simutenkov: The Application of Non-Discrimination Principles to Non-EU Nationals in European Sports», Suffolk Transnational Law Review, vol. 30, 2006, núm. 1, pp. 203-232.

102 Esa «traslación» de la normativa antidopaje de la AMA al Derecho interno facilita la intervención de los jueces internos en estos casos, y por tanto, el agotamiento de los recursos internos que se interponen para tratar de anular sus efectos.

103 Se trata de los asuntos Federación Nacional de Sindicatos Deportivos y otros c. Francia, demanda núm. 48151/11 (el caso fue comunicada a las partes el 26 de junio de 2013) y Longo y Ciprelli c. Francia, demanda núm. 77769/13 (el caso fue comunicado a las partes el 18 de junio de 2014).

104 Se trata de los asuntos Bakker c. Suiza, demanda núm. 7198/07 (el caso fue comunicado a las partes el 7 de septiembre de 2013), Mutu c. Suiza, demanda núm. 40575/10 (el caso fue comunicado a las partes el 12 de febrero de 2013) y Petchstein c. Suiza, demanda núm. 67474/10 (el caso fue comunicado a las partes el 13 de febrero de 2013). 
siguen ante órganos disciplinarios deportivos ha sido aceptada, por lo demás, por el propio $\mathrm{CAS}^{105}$.

La admisibilidad de estos asuntos supondría, en mi opinión, una excelente oportunidad para que el TEDH afirmase la vigencia, en el ámbito deportivo, de los derechos fundamentales protegidos por el Convenio y, en definitiva, de la aplicación de algunos de los estándares del DIDH en dicho ámbito ${ }^{106}$.

\section{CONCLUSIONES}

Este trabajo ha tratado de mostrar que, desde diferentes ángulos, y a pesar de la tradicional resistencia de las organizaciones deportivas, naturalmente defensoras de una autonomía reguladora y organizativa plena, el Derecho internacional público no ha permanecido al margen de «lo deportivo». En primer lugar, porque algunas de sus normas — tratados internacionales, resoluciones de diversas Organizaciones Internacionales- tienen como objetivo la imposición a los Estados de obligaciones directamente relacionadas con cuestiones de esa índole. La lucha contra el dopaje en el deporte, asumida no solo por las organizaciones deportivas, sino también por Estados y Organizaciones Internacionales como un objetivo propio, constituye, sin duda, un ejemplo claro en este sentido.

Junto a este grupo de normas internacionales, se ha identificado aquí al deporte como un instrumento al servicio de la implementación de funciones propias del Derecho internacional, de grandes objetivos de la Comunidad internacional: la promoción de la paz y el desarrollo, de una parte, y de los derechos humanos, de otra. Es muy relevante también, por último, la discusión sobre el papel que está llamado a jugar el DIDH en relación con la protección de los derechos fundamentales de los deportistas. Sometidos tradicionalmente a procedimientos no judiciales de arreglo de controversias, el llamado arbitraje deportivo, desarrollados de acuerdo con normas emanadas de las propias organizaciones deportivas, los deportistas pueden verse desprotegidos si aquellas normas no respetan estándares internacionalmente aceptados de protección de derechos humanos. Para evitar esa desprotección se ha defendido aquí la intervención de los órganos de protección internacional de derechos humanos y, en particular, la del TEDH. Dicha intervención no debe suponer un obstáculo, quizás más bien al contrario, al desarrollo por parte de los órganos deportivos arbitrales, incluido el CAS, de

105 Que ha afirmado, al respecto, lo siguiente: «La Formation arbitrale est consciente du fait que certaines garanties procédurales découlant de l'article 6.1 de la $C E D H$, dans les litiges portant sur des droits et obligations de caractère civil, sont indirectement applicables meme devant un tribunal arbitral —d'autant plus en matière disciplinaire—»: cfr. el apartado 24 del Laudo Arbitral 2011/A/2433, Amadou Diakite c. Fédération Internationale de Football Association (FIFA), de 8 de marzo de 2012, disponible en http:// www.tas-cas.org/en/jurisprudence/archive.html.

106 Lo que nos sitúa, por lo demás, en el ámbito de la extensión de la eficacia de los derechos fundamentales a las relaciones entre particulares. 
un Derecho no dispositivo, una suerte de ius cogens, específico en materia de derechos humanos ${ }^{107}$.

Los avances y desarrollos mencionados permitirían hablar, en mi opinión, de un Derecho internacional del deporte, al que cabría definir como el conjunto de principios, reglas y procedimientos que garantizan la consecución de las mencionadas funciones del Derecho internacional.

\section{RESUMEN}

\section{¿UN DERECHO INTERNACIONAL DEL DEPORTE? REFLEXIONES EN TORNO A UNA RAMA DEL DERECHO INTERNACIONAL IN STATU NASCENDI}

Este trabajo pretende contribuir a la reflexión académica sobre la existencia y funciones de un Derecho internacional del deporte. Con ese propósito, se analizan en el mismo los desarrollos normativos internacionales tendentes a la consecución de objetivos propios del entorno deportivo, de un lado, y de objetivos clásicos del Derecho internacional, de otro. El estudio presta especial atención al papel que está llamado a jugar en este ámbito el Derecho Internacional de los Derechos Humanos en lo que hace tanto a la posible conformación de un derecho humano al deporte, como a la aplicabilidad de sus normas para lograr la efectiva protección de los derechos fundamentales de los deportistas.

Palabras clave: Derecho internacional del deporte, regulación internacional del deporte, pluralismo jurídico, derechos humanos, derecho al deporte, lucha contra el dopaje, solución de controversias deportivas, arbitraje deportivo.

\section{ABSTRACT \\ AN INTERNATIONAL SPORTS LAW? SOME REFLECTIONS ABOUT A BRANCH OF PUBLIC INTERNATIONAL LAW IN STATU NASCENDI}

This work aims to contribute to the academic reflection about the existence and functions of a Public International Sports Law. It examines the main international normative developments aiming to the achievement of sporting objectives, on the one side, and of typical objectives of International Law, on the other. The study pays special attention to the relationship between International Human Rights Law and sport. In this regard, it analyses both the progressive conformation of a human right to sport, and how that branch of International Law serves to the protection of sportspeople's fundamental rights.

Keywords: International sports law, international regulation of sport, legal pluralism, human rights, human right to sport, fight against doping, sporting related disputes settlement, sport arbitration proceeding.

107 «Arbitration instances must move beyond concrete contractual terms in order to take environmental consequences and human rights complications into account as part of a specific ius non dispositivum; equally, courts of arbitration must apply their own ordre public [...] At the same time, if arbitration courts fail to take into account ius cogens, it may well be that national courts will not enforce their decision", Fischer-Lescano, A. y Teubner, G., op. cit., nota 26, pp. 1038-1039. 